\title{
Nail Apparatus Melanoma: Experience of 10 Years in a Single Institution
}

\author{
Desiree Ji Re Lee Samia Trigo Arbache Maria Victória Quaresma \\ Marcello Menta Simonsen Nico Tatiana Villas Boas Gabbi \\ Department of Dermatology, University of São Paulo, São Paulo, Brazil
}

\section{Keywords}

Nail apparatus melanoma - Melanonychia - Ungual

melanoma · Hutchinson's sign · Nail melanoma

epidemiology

\begin{abstract}
Background: Nail apparatus melanoma (NAM) is rare. The higher mortality reported in the literature is most likely due to advanced disease associated with delayed diagnosis and treatment. Objective: All patients diagnosed with NAM were followed at a single reference center during a period of 10 years, with emphasis on dermatological and histological findings. Clinical outcomes were included. Methods: A retrospective review of medical records, photographs, and histopathological examination. Results: $73.7 \%$ of the patients were female and their mean age was 47 years. Caucasian and African-American patients had a similar incidence (47.4\%). There was only 1 Asian patient in this study (5.3\%). All patients presented with nail plate pigmentation. The mean prediagnosis duration was 33 months. A total of $63.2 \%$ patients had in situ melanoma and an average Breslow index of $2.18 \mathrm{~mm}$ in invasive cases. Fifteen patients underwent conservative surgery and 3 underwent phalanx amputation. All patients survived, and 4 have had more than a 5-year follow-up. Conclusion: In situ lesions showed longitudinal bands or total melanonychia with no nail dystrophy. Invasive cases presented with dystrophic lesions (longitudinal split-
\end{abstract}

\section{KARGER}

(c) 2018 S. Karger AG, Basel

E-Mail karger@karger.com

www.karger.com/sad ting of the nail). Conservative surgery provides a good option without worsening the prognosis. All dermatologists should be aware of early signs of NAM, since prognosis depends on early treatment.

(c) 2018 S. Karger AG, Basel

\section{Introduction}

Nail apparatus melanoma (NAM) can be either subungual or periungual, depending on whether it is located under the nail or around the nail, and most arise from abnormal nail matrix melanocytes $[1,2]$. It was first described by Boyer [3] in 1834 and then by Hutchinson [4] in 1886. NAM is considered as a subgroup of acral lentiginous melanomas, comprising only $0.7-3.5 \%$ of all forms of melanoma [5-7].

Initial clinical manifestations comprise a longitudinal melanonychia that may progressively enlarge and involve the whole plate. Periungual pigmentation (Hutchinson's sign) may be present. More advanced cases may show partial or complete nail plate destruction [8]. The presence of multiple shades of brown and black, homogenous black pigmentation, melanonychia with width of $3 \mathrm{~mm}$ or more or an irregular or blurred border must raise suspicion for melanoma $[9,10]$.

Despite being rare, NAM accounts for a disproportionately higher mortality when compared with melano- 
Table 1. Nail apparatus melanoma clinical features

\begin{tabular}{|c|c|}
\hline \multicolumn{2}{|l|}{ Sex, $n(\%)$} \\
\hline Male & $5 / 19(26.3)$ \\
\hline Female & $14 / 19$ \\
\hline \multicolumn{2}{|l|}{ Age, years } \\
\hline Range & $8-80$ \\
\hline Mean & 47 \\
\hline \multicolumn{2}{|l|}{ Ethnicity, $n(\%)$} \\
\hline Caucasian & $9 / 19(47.4)$ \\
\hline African-American & $9 / 19(47.4)$ \\
\hline Asian & $1 / 19(5.3)$ \\
\hline \multicolumn{2}{|l|}{ Lesion site, $n(\%)$} \\
\hline Fingernail & $12 / 19(63.2)$ \\
\hline Toenail & 7/19 (36.8) \\
\hline Left side & $8 / 19(42.1)$ \\
\hline Right side & $11 / 19(57.9)$ \\
\hline First fingernail & $9 / 19(47.4)$ \\
\hline First toenail & $5 / 19(26.3)$ \\
\hline Second fingernail & $1 / 19(5.3)$ \\
\hline Second toenail & $1 / 19(5.3)$ \\
\hline Fourth fingernail & $1 / 19(5.3)$ \\
\hline Fifth fingernail & $2 / 19(10.5)$ \\
\hline Fifth toenail & $1 / 19(5.3)$ \\
\hline \multicolumn{2}{|c|}{ Clinical manifestations at initial diagnosis, $n(\%)$} \\
\hline Nail dystrophy & $8 / 19(42.1)$ \\
\hline Periungual pigmentation & $9 / 19(47.4)$ \\
\hline Eponychium & $5 / 19(26.3)$ \\
\hline Lateral nail fold & $5 / 19(26.3)$ \\
\hline Hyponychium & $5 / 19(26.3)$ \\
\hline Total nail pigmentation & $8 / 19(42.1)$ \\
\hline Partial nail pigmentation & $11 / 19(57.9)$ \\
\hline Nail bed mass & $2 / 19(10.5)$ \\
\hline Amelanotic lesion & $0 / 19(0.0)$ \\
\hline \multicolumn{2}{|l|}{ Prediagnosis duration, months } \\
\hline Range & $3-120$ \\
\hline Mean & 33 \\
\hline \multicolumn{2}{|c|}{ Extracutaneous involvement at diagnosis, $n(\%)$} \\
\hline Lymph node involvement & $3 / 19(15.8)$ \\
\hline Visceral involvement & $0 / 19(0.00)$ \\
\hline \multicolumn{2}{|l|}{ AJCC stage at diagnosis, $n(\%)$} \\
\hline 0 & $12 / 19(63.2)$ \\
\hline I & $2 / 19(10.5)$ \\
\hline II & $2 / 19(10.5)$ \\
\hline III & $3 / 19(15.8)$ \\
\hline IV & $0 / 19(0.00)$ \\
\hline \multicolumn{2}{|l|}{ History, $n(\%)$} \\
\hline Family & $0 / 19(0.00)$ \\
\hline Personal & $1 / 19(5.3)$ \\
\hline
\end{tabular}

ma elsewhere, with a 5-year survival rate of about $55 \%$ [11]. Clinicopathological features affecting an NAM prognosis are: age at diagnosis, number of dermal mitoses, Breslow thickness, ulceration, amelanosis, and vascular invasion $[8,12,13]$. Tan et al. [14] suggest that a higher American Joint Committee on Cancer (AJCC) stage is
Table 2. Comparison of histopathological features

\begin{tabular}{lc}
\hline Thickness, $n(\%)$ & \\
$\quad \leq 1 \mathrm{~mm}$ & $14 / 19(73.7)$ \\
$>1$ to $\leq 2 \mathrm{~mm}$ & $1 / 19(5.3)$ \\
$>2$ to $\leq 3 \mathrm{~mm}$ & $3 / 19(15.8)$ \\
$>3$ to $\leq 4 \mathrm{~mm}$ & $0 / 19(0.0)$ \\
$>4(\mathrm{~T} 4) \mathrm{mm}$ & $1 / 19(5.3)$ \\
In situ melanoma, $n(\%)$ & $12 / 19(63.2)$ \\
Ulceration, $n(\%)$ & $3 / 19(15.8)$ \\
High mitotic rate $>5 / \mathrm{mm}^{2}, n(\%)$ & $2 / 19(10.5)$ \\
Vertical growth phase, $n(\%)$ & $7 / 19(36.8)$ \\
Regression, $n(\%)$ & $0 / 19(0.0)$
\end{tabular}

the only significant predictor of a lower survival. Early excision is the only treatment known to increase survival thus far $[12,14]$. Diagnosis plays a crucial role and dermatologists should be aware of early signs of NAM.

In this study, we report all patients diagnosed with NAM who were followed at a single reference center during a period of 10 years, with emphasis on dermatological and histological findings and clinical outcomes.

\section{Methods}

A search was conducted in our database for cases in which the diagnosis of NAM was suspected between August 2007 and February 2017. The inclusion criterion was a diagnosis of melanoma in the nail apparatus confirmed by histopathology and immunohistochemistry results. All biopsy slides were reviewed. NAM was defined as a melanoma arising in the nail bed, nail matrix, or periungual tissue.

A retrospective review of all patients' medical records, photographs, and histopathological examination was performed to analyze the following data: sex, age at diagnosis, ethnicity, lesion site, initial clinical manifestation, family or personal history of previous melanoma, prediagnosis duration, treatment, and patient survival. The following histopathological characteristics were reviewed: subtype, Breslow thickness, ulceration, mitotic rate, regression, and vertical growth phase. The disease stage was determined according to the AJCC classification.

Data were collected retrospectively from medical records. Patients did not undergo further examination or additional procedures or appointments, aside from the usual visits.

\section{Results}

A retrospective review of the Hospital das Clinicas via the São Paulo database identified 19 patients diagnosed with NAM who were treated between August 2007 and February 2017. All data are available in Tables 1 and 2 and Figures 1-5. 


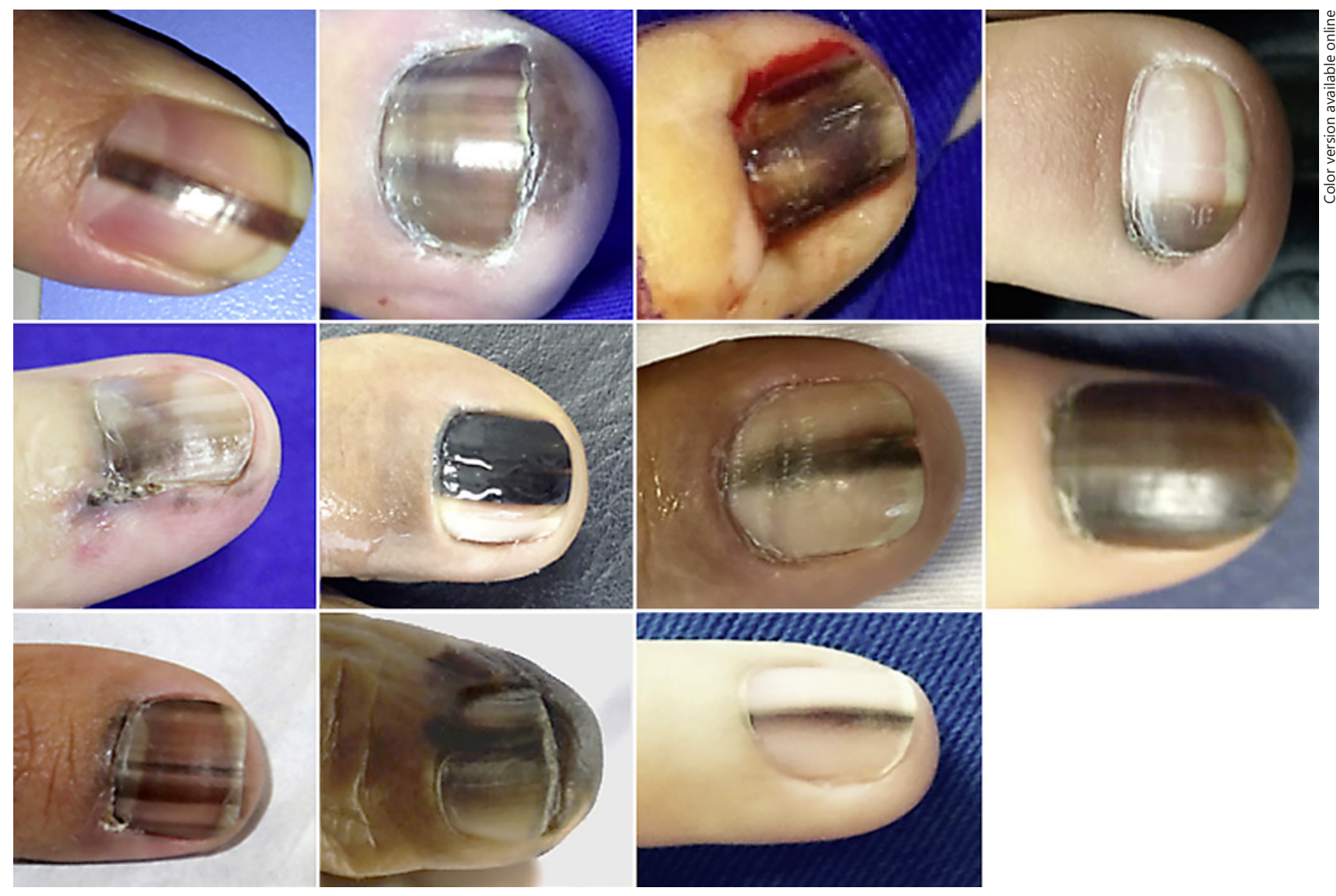

Fig. 1. Stage 0 - in situ melanoma.

Fig. 2. Stage I.

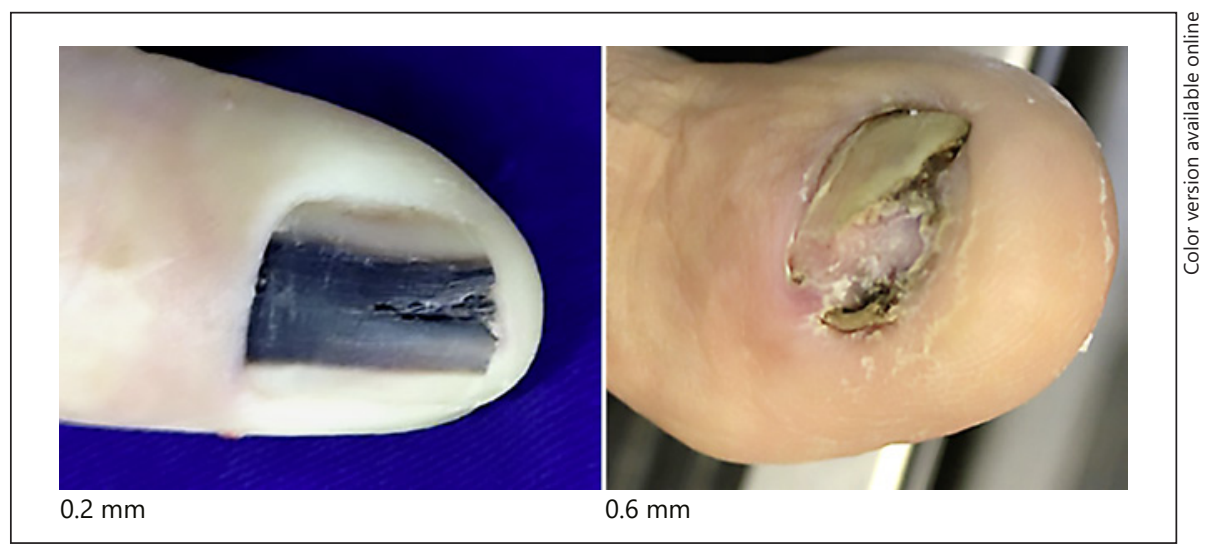

There were 5 male and 14 female patients, with age ranging from 8 to 80 years (mean age 47 years). Nine patients were Caucasian, 9 African-American, and 1 was Asian. Twelve had fingernail involvement and 7 had toenail involvement. The right side was more prevalent than the left side (11:8). The first fingernail was the most prevalent ( 9 patients) and the first toenail was the second most prevalent (5 cases).

NAM clinical manifestations vary. Partial to total nail pigmentation and periungual pigmentation were ob- 
Fig. 3. Stage II.
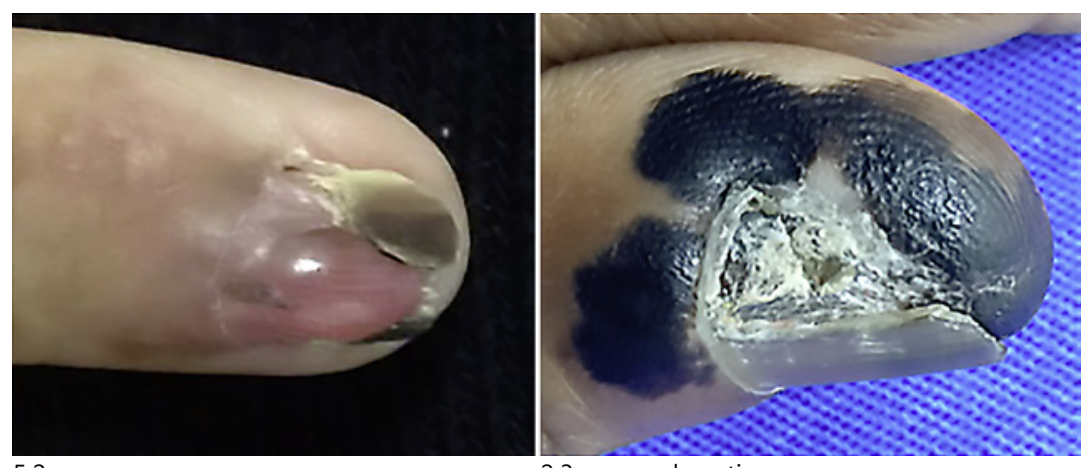

$2.3 \mathrm{~mm}+$ ulceration

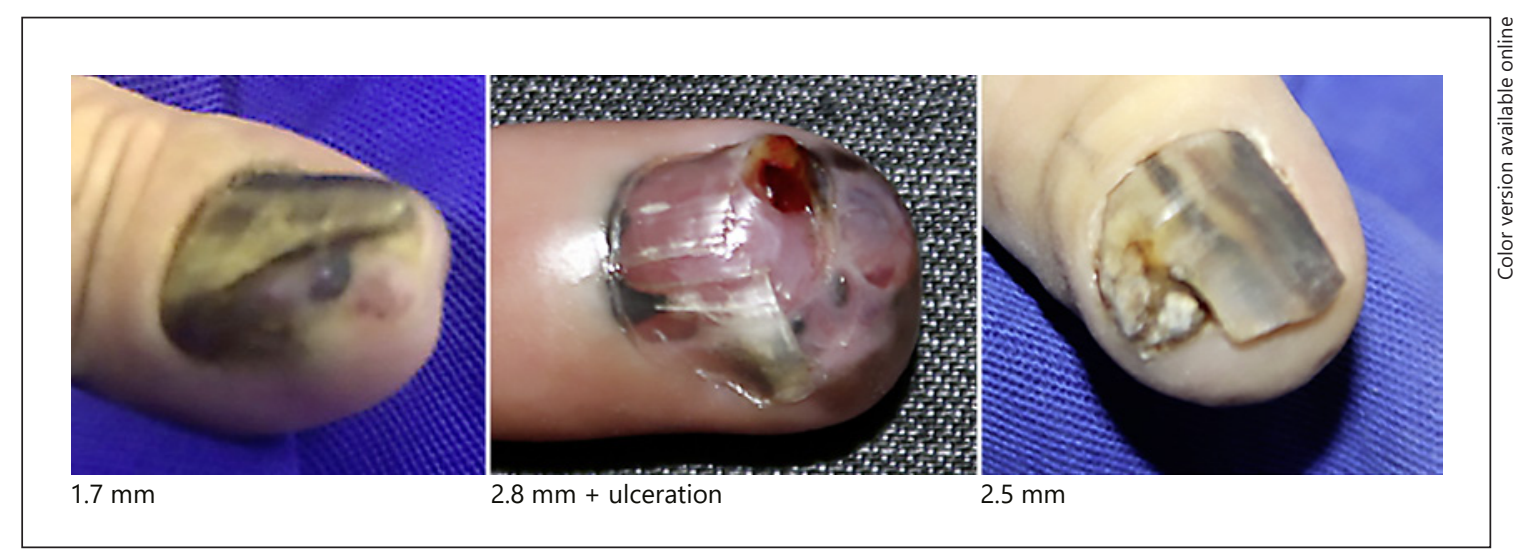

Fig. 4. Stage III.

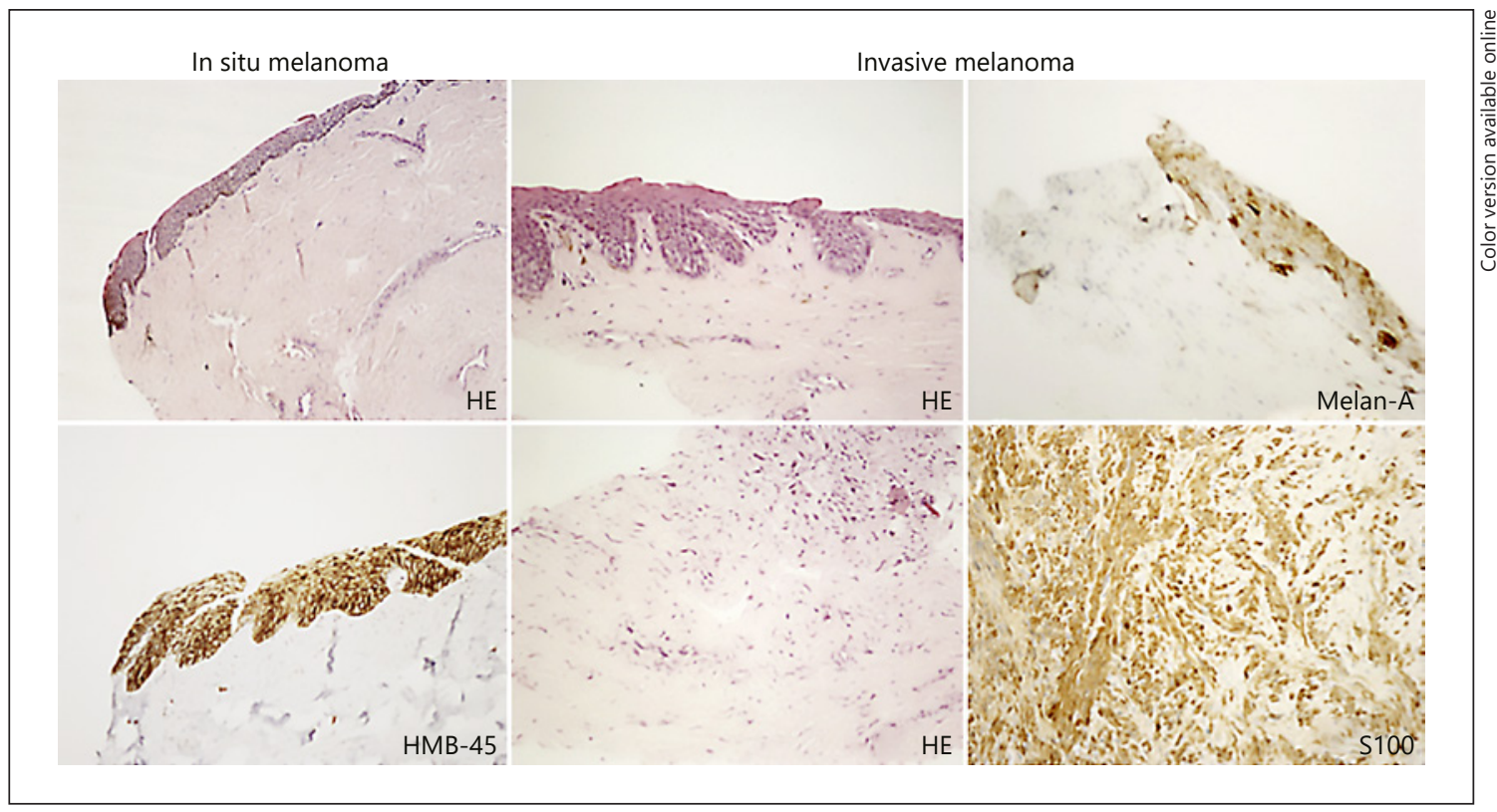

Fig. 5. In situ melanoma versus invasive melanoma. 
served in in situ cases. Invasive NAM presented nail pigmentation, nail dystrophy, and 1 had nail bed mass.

The mean prognosis duration was 33 months (3-120 months). There was 1 patient with a history of cutaneous melanoma in our series.

There were 12 in situ melanomas, 2 with a thickness $>1 \mathrm{~mm}, 1$ between 1 and $2 \mathrm{~mm}, 3$ between 2 and $3 \mathrm{~mm}$, and 1 with more than $4 \mathrm{~mm}$. Three cases had histological ulceration and 2 cases presented a high mitotic rate. A vertical growth phase was observed in 7 patients, but regression was not observed. There were 3 cases with lymph node involvement.

On the left side of Figure 5, an in situ melanoma with atypical melanocytes ascension is shown. On the right side, an invasive melanoma with melanocytes with nuclear retraction with pigmentary effusion in the superficial dermis is shown. Analyzing the underlying dermis, a fusocellular proliferation was observed. Melan-A marked melanocytes in the epithelium of the matrix, but not in the dermis. Only S100 highlighted positivity of the fusocellular component of the dermis.

\section{Discussion}

There are still few studies on NAM. In the 10 years of this study, only 19 patients were diagnosed with NAM in our Dermatology Center, where 20,000 [15] new patients are seen every year.

In our series, there was a threefold female predominance. The literature is unclear about which gender is more affected [1]. In Japan, Korea, and Taiwan, there is a male predominance [16-18], whereas a female predominance is observed in Western countries $[6,19,20]$.

The patients had a mean age of 47 years, which is younger than in the literature (53-66 years) $[18,21-23]$. NAM is more frequent between the ages of 50 and 70 years [1], but in rare occasions can also be observed in children $[24,25]$. More than half of the subjects were younger than 50 years, including an 8-year-old child.

As for ethnicity, Caucasian and African-American patients had a similar incidence (47.4\%). There was only 1 Asian patient in this study (5.3\%). In absolute numbers, NAM incidence in Caucasians and African-Americans is very similar $[11,26]$, although NAM represents $20 \%$ of all melanoma cases in African-Americans and 1.5-2\% of all melanoma cases in Caucasians $[1,21,26,27]$.

In our study, a significant amount of time passed from the perception of the lesion by the patient to the diagnosis, with a mean duration of 33 months (range 3-120).
Nevertheless, it is a shorter period of time compared to 61 and 55 months in the studies conducted by Lee et al. [18] and High et al. [21], respectively. NAM is often only diagnosed many years or even decades after the initial clinical manifestations. A long prediagnosis duration can contribute to a poor prognosis, as reported in the literature.

Most of the studied lesions were located on the first fingernail (47.4\%) and first toenail (26.3\%). In the literature, the first fingernail is also the most affected digit, followed by the first toenail [1]. Fingernail involvement was three times more frequent than toenails, as seen in previous studies $[20,22,28]$. Whether trauma plays an important role is not clear, but $47.4 \%$ of patients of this study reported a history of trauma preceding NAM $[28,29]$.

All patients showed some degree of melanonychia, and $42.1 \%$ had total nail pigmentation. Hutchinson's sign was observed in $47.4 \%$, of which $26.3 \%$ were on the proximal nail fold, $26.3 \%$ on the lateral nail fold, and $26.3 \%$ on the hyponychium. Nail dystrophy was observed in $42.1 \%$ and nail bed mass in $10.5 \%$ patients. There were no cases of amelanotic lesions in this study.

In this series, we observed that in situ lesions showed longitudinal bands or total melanonychia, but no nail dystrophy. All invasive cases presented with some degree of dystrophy, at least a minimum of longitudinal nail splitting.

No patients had a familiar history of melanoma, and only 1 patient had a history of skin melanoma. At diagnosis, $15.8 \%$ had lymph node involvement and no visceral involvement was observed. The AJCC stage [30] proportion at diagnosis was $63.2 \%$ in stage $0,10.5 \%$ in stage I, $10.5 \%$ in stage II, $15.8 \%$ in stage III, and 0 in stage IV.

NAM histologic criterion is still under discussion. The presence of melanocytes in the suprabasal position is physiological in the matrix within the lower $2-4$ germinative cell layers. Histological examination of nail melanoma biopsy can be difficult, and immunohistochemical investigations are often helpful [31]. Histologic examination revealed a predominance of in situ melanoma (63.2\%). In situ melanoma is characterized by an increased number of melanocytes in the basal cell layer and single melanocytes predominate over the nest in most fields. Nuclear atypia (nuclear enlargement, angular and hyperchromatic nuclei, and prominent nucleolus) are present as a pagetoid spreading. Invasive melanoma is characterized by atypical melanocytes also invading the dermis, which usually starts in the nail bed $[32,33]$. The average depth of invasive cases was $2.18 \mathrm{~mm}$, in contrast 


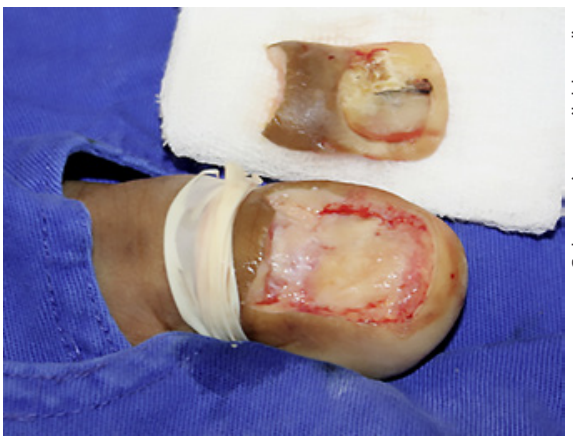

Fig. 6. Conservative surgery of in situ nail apparatus melanoma.

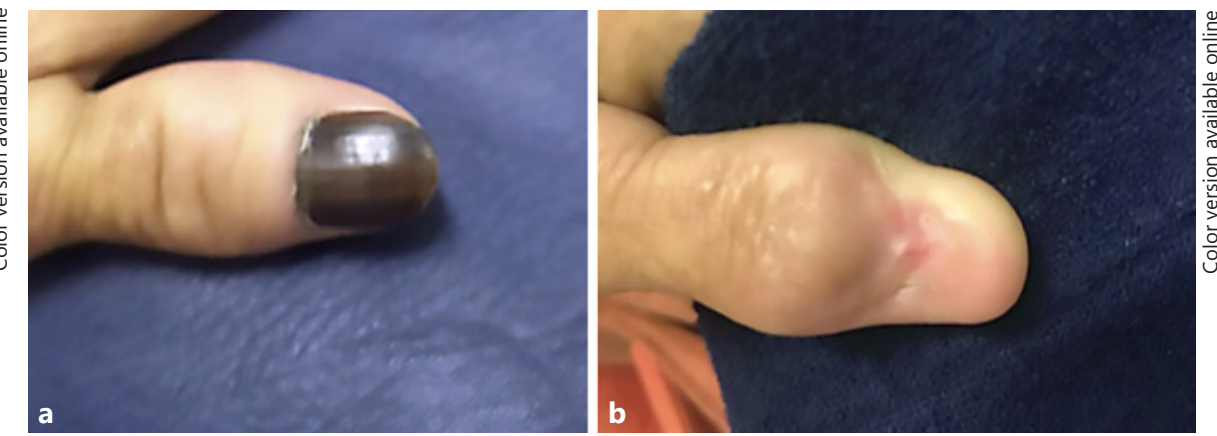

Fig. 7. Conservative surgery. a Preoperative. b Postoperative. to $4.80 \mathrm{~mm}$ in the study by Banfield et al. [34] including 105 patients.

Melanocytes can be better observed via immunohistochemical stains, including S100, HMB-45, Melan-A, and MiTF. The HMB- 45 was the most intense marker in most cases. The sensitivity of the $\mathrm{S} 100$ protein was high in the dermal component of the invasive melanoma, whereas its intraepidermal component was weak or negative for this marker.

Traditional first-line therapy for NAM used to be phalanx amputation [35, 36]. More recently, a conservative nonamputative treatment method has been considered in cases of minimally invasive NAM or in situ NAM [37]. It consists of a wide excision of the whole nail apparatus with safety margins $[1,35,36,38]$. In this study, only 3 patients with a more advanced disease underwent phalanx amputation, whereas the 15 others underwent conservative surgery (Fig. 6, 7), and 1 is still under treatment with a surgical approach scheduled.

All 19 patients survived, of which 4 were diagnosed more than 5 years prior. Fifteen patients were diagnosed in the last 5 years and are still being followed. All are without signs of recurrence. Nevertheless, NAM is often related with a poor prognosis. The reported 5 -year survival rates vary between 16 and $76 \%[6,12,20,39-42]$.

\section{Conclusion}

Due to its rarity, there are still few studies that have examined NAM. The literature is still unclear as to whether a poor prognosis associated with NAM is due to an intrinsic aggressiveness of the tumor or a delay in diagnosis. In this study, an earlier diagnosis was made, since most cases were in situ NAM, and achieved a better outcome

than the rates described in the literature. This reinforces the notion that early treatment is crucial for prognosis. In situ lesions showed longitudinal bands or total melanonychia but no nail dystrophy, whereas all invasive cases presented with some degree of dystrophy, at least with a minimum of longitudinal nail splitting. Conservative surgery was performed for all in situ melanoma patients and did not worsen the prognosis with much less morbidity. In conclusion, physicians and dermatologists, in particular, should be aware of the early signs of NAM, since the prognosis depends on early treatment. Although more studies need to be performed, we hope to have improved the knowledge regarding NAM.

\section{Statement of Ethics}

All patients signed an informed consent allowing the publication of this information.

\section{Disclosure Statement}

The authors have no conflict of interest to disclose. There was no financial sponsorship.

\section{References}

Skin Appendage Disord 2019;5:20-26 DOI: $10.1159 / 000488722$
1 Haneke E: Ungual melanoma - controversies in diagnosis and treatment. Dermatol Ther 2012;25:510-524.

2 Saida T: Heterogeneity of the site of origin of malignant melanoma in ungual areas: "subungual" malignant melanoma may be a misnomer. Br J Dermatol 1992;126:529.

3 Boyer A: Fungus Hematide du petit digit. Ganz Med Paris 1834:212. 
4 Hutchinson J: Melanosis often not black: melanotic whit-low. Br Med J 1886;1:491.

5 Izumi M, Ohara K, Hoashi T, et al: Subungual melanoma: histological examination of 50 cases from early stage to bone invasion. J Dermatol 2008;35:695-703.

6 Eberhard P, Kleiner H, Bodeker RH: Epidemiologie und Prognose subungualer Melanome. Hautarzt 1992;43:286-290.

7 Shaw JH, Koea JB: Acral (volar-subungual) melanoma in Auckland, New Zealand. Br J Surg 1988;75:69-72.

8 Banfield CC, Dawber RP: Nail melanoma: a review of the literature with recommendations to improve patient management. $\mathrm{Br} \mathrm{J}$ Dermatol 1999;141:628-632.

9 Levit EK, Kagen MH, Scher RK, Grossman M, Altman E: The ABC rule for clinical detection of subungual melanoma. J Am Acad Dermatol 2000;42:269-274.

10 Baran R, Kechijian P: Hutchinson's sign: a reappraisal. J Am Acad Dermatol 1996;34:8790

11 Thai KE, Young R, Sinclair RD: Nail apparatus melanoma. Australas J Dermatol 2001;42: 71.

12 Blessing K, Kernohan NM, Park KG: Subungual malignant melanoma: clinicopathological features of 100 cases. Histopathology 1991; 19:425-429.

13 Rigby HS, Briggs JC: Subungual melanoma: a clinico-pathological study of 24 cases. $\mathrm{Br}$ J Plast Surg 1992;45:275-278

14 Tan KB, Moncrieff M, Thompson JF, et al: Subungual melanoma: a study of 124 cases highlighting features of early lesions, potential pitfalls in diagnosis, and guidelines for histologic reporting. Am J Surg Pathol 2007; 31:1902-1912.

15 Bertanha F, Nelumba EJP, Freiberg AK, Samorano LP, Festa NC: Profile of patients admitted to a triage dermatology clinic at a tertiary hospital in São Paulo, Brazil. An Bras Dermatol 2016;91:318-325.

16 Roh M R, Kim J, Chung KY: Treatment and outcomes of melanoma in acral location in Korean patients. Yonsei Med J 2010;51:562_568.

17 Chang JWC: Cutaneous melanoma: Taiwan experience and literature review. Chang Gung Med J 2010;33:602-612.
18 Lee W, et al: Nail apparatus melanoma: a comparative, clinicoprognostic study of the initial clinical and morphological characteristics of 49 patients. J Am Acad Dermatol 2015; 73:213-220.

19 Bradford PT, Goldstein AM, McMaster ML, Tucker MA: Acral lentiginous melanoma: incidence and survival patterns in the United States, 1986-2005. Arch Dermatol 2009;145: 427-434.

20 Phan A, Touzet S, Dalle S, Ronger-Savle S, Balme B, Thomas L: Acral lentiginous melanoma: a clinicoprognostic study of 126 cases. Br J Dermatol 2006;155:561-569.

21 High WA, Quirey RA, Guillén DR, Munõz G, Taylor RS: Presentation, histopathologic findings, and clinical outcomes in 7 cases of melanoma in situ of the nail unit. Arch Dermatol 2004;140:1102-1106.

22 Minagawa A, Omodaka T, Koga H, Yokokawa Y, Uhara H, Okuyama R: Nail apparatus melanoma thickness is associated with side and age. Br J Dermatol 2017;177:e65-e66.

23 Cohen T, Busam KJ, Patel A, Brady MS: Subungual melanoma: management considerations. Am J Surg 2008;195:244-248.

24 Tosti A,Piraccini BM, Cagalli A, Haneke E: In situ melanoma of the nail unit in children: report of 2 cases in Caucasian fair skinned children. Pediatr Dermatol 2012;29:79-83.

25 Goettman-Bonvallot S, Andre J, Belaich S: Longitudinal melanonychia in children: a clinical and histopathologic study of 40 cases. J Am Acad Dermatol 1999;41:17-22.

26 Kato T, Suetake T, Sugiyama Y, Tabata N, Tagami $\mathrm{H}$ : Epidemiology and prognosis of subungual melanoma in 34 Japanese patients. $\mathrm{Br}$ J Dermatol 1996;134:383-387.

27 Baran R, Dawber RPR: Diseases of the Nail and Their Management, ed 2. Oxford, Blackwell Science, 1994, pp 483-497.

28 Seui M, Takematsu H, Hosokawa M, et al: Acral melanoma in Japan. J Invest Dermatol 1983;80:56s-60s.

29 Rangwala S, Hunt C, Modi G, Krishnan B, Orengo I: Amelanotic subungual melanoma after trauma: an unusual clinical presentation. Dermatol Online J 2011;17:8.
30 Edge SB, Compton CC: The American Joint Committee on Cancer: the 7th Edition of the AJCC Cancer Staging Manual and the Future of TNM. Ann Surg Oncol 2010;17:1471.

31 Ruben BS: Pigmented lesions of the nail unit: clinical and histopathologic features. Semin Cutan Med Surg 2010;29:148-158.

32 Fernandez-Flores A, Cassarino DS: Histopathological diagnosis of acral lentiginous melanoma in early stages. Ann Diagn Pathol 2017;26:64-69.

33 Amin B, Nehal KS, Jungbluth AA, et al: Histologic distinction between subungual lentigo and melanoma. Am J Surg Pathol 2008;32: 835-843.

34 Banfield CC, Redburn JC, Dawber RPR: The incidence and prognosis of nail apparatus melanoma. A retrospective study of $105 \mathrm{pa}-$ tients in four English regions. Br J Dermatol 1998;139:276-279.

35 Sureda N, Phan A, Poulalhon N, Balme B, Dalle S, Thomas L: Conservative surgical management of subungual (matrix derived) melanoma: report of seven cases and literature review. Br J Dermatol 2011;165:852-858.

36 Cochran AM, Buchanan PJ, Bueno RA Jr Neumeister MW: Subungual melanoma: a review of current treatment. Plast Reconstr Surg 2014;134:259-273.

37 Haneke E, Binder D: Subungual melanoma with streaky nail pigmentation (in German). Hautarzt 1978;29:389-391.

38 Neczyporenko F, Andre J, Torosian K, Theunis A, Richert B: Management of in situ melanoma of the nail apparatus with functional surgery: report of 11 cases and review of the literature. J Eur Acad Dermatol Venereol 2014;28:550-557.

39 Kuchelmeister C, Schaumburg-Lever G, Garbe C: Acral cutaneous melanoma in Caucasians: clinical features, histopathology and prognosis in 112 patients. Br J Dermatol 2000; 143:275-280.

40 Panizzon R, Krebs A: Das subunguale maligne Melanoma. Hautarzt 1980;31:132-140.

41 Patterson RH, Helwig EB: Subungual malignant melanoma: a clinical-pathologic study. Cancer 1980;46:2074-2087.

42 Heaton KM, el-Naggar A, Ensign LG, Ross MI, Balch CM: Surgical management and prognostic factors in patients with subungual melanoma. Ann Surg 1994;219:197-204. 